\title{
Identification of metabolites of gardenin A in rat liver microsomes using ultra-high performance liquid chromatography coupled with linear ion-trap Orbitrap mass spectrometry
}

\author{
Rui Jun Cai, Jie Wei*, Feng Ling Jing, Gui Zhen Zhao and Yan Zhang \\ Department of Pharmacy, The People's Hospital of Jiuquan, Jiuquan, GanSu 735000, China \\ *For correspondence: Email: 119276645@qq.com, 1308320859@qq.com; Tel: +86-15293722809

\begin{abstract}
Purpose: To identify the metabolites of gardenin $A(G A)$ in rat liver microsomes (RLMs) using ultra-high performance liquid chromatography coupled with linear ion-trap Orbitrap mass spectrometry (UHPLCLTQ-Orbitrap).

Methods: The sample was prepared by incubating GA $(100 \mu \mathrm{g} / \mathrm{mL})$ with $R L M s(0.5 \mathrm{mg} / \mathrm{mL})$ for $8 \mathrm{~h}$. Then $5 \mu L$ of the sample was injected into UHPLC-LTQ- orbitrap mass spectrometer. The metabolites of GA were tentatively identified based on accurate mass measurements, fragmentation patterns, chromatographic retention times, and bibliography data.

Results: A total of 12 metabolites were detected and identified. Based on their structures, the main reactions in the metabolism of GA are de-methoxylation and de-methylation.

Conclusion: This is the first report on in vitro metabolites of GA. These results are considered very helpful for better comprehension of the metabolism of GA and its pharmacological effects.
\end{abstract}

Keywords: Gardenin A, Metabolites, UHPLC-LTQ-Orbitrap, Rat Liver microsomes

Tropical Journal of Pharmaceutical Research is indexed by Science Citation Index (SciSearch), Scopus, International Pharmaceutical Abstract, Chemical Abstracts, Embase, Index Copernicus, EBSCO, African Index Medicus, JournalSeek, Journal Citation Reports/Science Edition, Directory of Open Access Journals (DOAJ), African Journal Online, Bioline International, Open-J-Gate and Pharmacy Abstracts

\section{INTRODUCTION}

Murraya paniculata (L.) Jack, also called "qianlixiang in chinese" in China, belongs to the family Rutaceae. It is a very variable evergreen shrubby plant cultivated widely in gardens as an ornamental in many areas of China. The plant is officially listed in the Chinese Pharmacopoeia as a drug in Chinese Traditional medicine (TCM) [1]. Dried leaves or tender branches have been used all over China as a folk medicine due to the stimulant, astringent, antidysenteric, toothache remedy, and antidiarrheal [2-4]. Gardenin A (5hydroxy-6, 7, 8, 3', 4', 5'-hexamethoxyflavone, $\mathrm{GA})$, a hydroxylated polymethoxyflavonoid $(\mathrm{OH}-$ PMF), has been isolated from Murraya paniculata (L.) Jack [5-6]. Pharmacological studies indicate that it possesses variety of biological activities, such as anticancer and antiinflammatory effects [7-9].

Research on drug metabolism research is very important in the early phases of drug discovery and development. It is also important for minimizing the adverse effect of pharmaceuticals, and for maximizing their therapeutic value $[10,11]$. A previous report [12] demonstrated that 26 metabolites of GA were observed in vivo; these might be responsible for the pharmacological actions of GA. However, it is hard to establish the reliability of this observation, due to difficulties involved in obtaining enough 
metabolites in vivo. Thus, it is important to obtain GA metabolites in vitro. To the best of our knowledge, metabolites of GA have not been investigated in vitro.

High performance liquid chromatography coupled with mass spectrometry has become a popular, and indeed the main method for the structural characterization of drug metabolites in vivo and in vitro due to its high efficiency, sensitivity, and selectivity. Among several different LC/MS platforms, ultra-high performance liquid chromatography high-resolution mass spectrometry (UHPLC-HRMS) [13-15] such as UHPLC-LTQ-Orbitrap is especially useful for the characterization of drug metabolites due to its higher and faster separation and resolution capacities.

The present study was carried out identify the metabolites of GA in rat liver microsomes (RLMs) with a view to providing better understanding of the metabolism of the drug and its pharmacological effects.

\section{EXPERIMENTAL}

\section{Chemicals and reagents}

Gardenin A, 5-hydroxy-7, 3', 4', 5'tetramethoxyflavone and 5-hydroxy-7, 3', 4'trimethoxyflavone was purchased from Chengdu Biopurify Phytochemicals Co, Ltd (Sichuan, China). Acetonitrile, and methanol (HPLC grade) used were products of Fisher Scientific (Fisher, Fair Lawn, NJ, USA), and ultra-pure water used throughout the experiment was produced by a Milli-Q system (Millipore, Bedford, MA, USA). The $0.22 \mathrm{~mm}$ membranes used in the study were purchased from Waters Corporation (USA). Reduced form of nicotinamide adenine dinucleotide phosphate (NADPH) was supplied by Zhong Sheng Rui Tai Biotech (Beijing, China). RLMs were purchased from BD Biosciences (Bedford, MA, USA). All other reagents were of analytical grade.

\section{Microsome incubation}

Incubation conditions of microsome incubation experiment were established and controlled to provide a reproducible and linear rate of the metabolism in vitro. The incubation mixture in final volume of $1 \mathrm{~mL}$ contained GA $(100 \mu \mathrm{g} / \mathrm{mL})$, phosphate buffer $(0.1 \mathrm{~mol} / \mathrm{L}, \mathrm{pH} 7.4)$, magnesium chloride $(5 \mathrm{mM})$ and RLMs $(0.5 \mathrm{~g} / \mathrm{mL})$. The incubation mixture was pre-incubated for $5 \mathrm{~min}$ in a water bath at $37^{\circ} \mathrm{C}$ and reactions were initiated by addition of NADPH ( $1 \mathrm{mM})$. The reaction was terminated by adding $1 \mathrm{~mL}$ of ice- cold acetonitrile, vortexing and centrifuging at $15,000 \mathrm{rpm}$ for $10 \mathrm{~min}$ at $4{ }^{\circ} \mathrm{C}$. Aliquots of the supernatant were subjected to UHPLC-LTQOrbitrap MS to identify the metabolites. Blank samples were of the same composition as the test samples, but without GA. All samples were prepared in triplicate.

\section{Instrumentation and chromatographic conditions}

All UHPLC-MS analyses were carried out on LTQ/Orbitrap XL hybrid mass spectrometer (Thermo Electron, Bremen, Germany) equipped with an ESI source (Thermo Electron, Bremen, Germany). An Accela UHPLC system (ThermoFisher Scientific) was equipped with an autosampler, a vacuum de-gasser unit and a quaternary pump. Chromatographic separations were carried out on a BEH C18 column $(2.1 \times 50$ $\mathrm{mm}, 1.7 \mu \mathrm{m}$ ) at room temperature and a flow rate of $0.2 \mathrm{~mL} / \mathrm{min}$. The mobile phase consisted of solvent A (water) and solvent C (acetonitrile). The percentage of solvent $A$ was changed as follows: 0-2 min, $95 \%$ A; 2-3 min, 95-80 \% A; 320 min, 80 - $40 \%$ A; 20-21 min, 40-20\% A; 21-25 $\min , 20 \%$ A; 25-26 min, 20-95 \% A; 26-30 min, $95 \% \mathrm{~A}$; an aliquot of $5 \mu \mathrm{L}$ of the supernatant was injected into UHPLC-LTQ-Orbitrap MS.

The optimized operating parameters in the positive ion mode were as follows: capillary voltage of $25 \mathrm{~V}$, source voltage of $4.0 \mathrm{kV}$, capillary temperature of $350{ }^{\circ} \mathrm{C}$, sheath gas flow rate of 40 (arbitrary units), auxiliary gas flow rate of 20 (arbitrary units), and tube lens of $110 \mathrm{~V}$. Metabolites were detected by full-scan mass analysis from 100 to $800 \mathrm{~m} / \mathrm{z}$ at a resolving power of 30,000 with data-dependent $\mathrm{MS}^{2}$ analysis triggered by the three most-abundant ions from the precursor list of predicted metabolites followed by $\mathrm{MS}^{2}$ analysis of the most-abundant product ions. Collision-induced dissociation (CID) was performed with an isolation width of $2 \mathrm{Da}$. The collision energy was set to $35 \%$.

\section{Data processing}

Thermo Xcaliber 2.1 workstation (Thermo Fisher Scientific) was used for data acquiring and processing. In order to obtain as many fragment ions as possible, the peaks detected with intensity over 50,000 were selected for identification. The chemical formulas of all parent and fragment ions of the selected peaks were calculated from the accurate mass using a formula predictor by setting the parameters as follows: C [0 - 35], H [0 - 50], O [0 - 15], S [0 - 1], $N\left[\begin{array}{ll}0 & -3\end{array}\right]$, and Ring Double Bond (RDB) 
equivalent value [0 - 15]. Other elements such as $\mathrm{P}$ and $\mathrm{Br}$ were not considered as they were rarely present in the complex matrix. The maximum mass errors between the measured and the calculated values were $<5$ ppm. Blank RLMs samples were used as control to compare with the analyzed samples, and they were all processed under the same conditions.

\section{RESULTS}

\section{Fragmentation pathway of GA}

The parent ion showed a protonated ion $[\mathrm{M}+\mathrm{H}]^{+}$ at $\mathrm{m} / \mathrm{z}$ 419.13321 (-1.07 ppm, $\left.\mathrm{C}_{21} \mathrm{H}_{23} \mathrm{O}_{9}\right)$ in positive ion mode. Fragmentation of this parent ion at $\mathrm{m} / \mathrm{z} 389, \mathrm{~m} / \mathrm{z} 404, \mathrm{~m} / \mathrm{z} 358, \mathrm{~m} / \mathrm{z} 371$, and $\mathrm{m} / \mathrm{z} 386$ by the loss of the moiety $30\left(2 \mathrm{CH}_{3}{ }^{\circ}\right), 15$ $\left(\mathrm{CH}_{3}^{\circ}\right), 61\left(2 \mathrm{CH}_{3}{ }^{\circ}+\mathrm{OCH}_{3}^{\circ}\right), 48\left(2 \mathrm{CH}_{3}{ }^{\circ}+\mathrm{H}_{2} \mathrm{O}\right)$, and $33\left(\mathrm{CH}_{3}{ }^{\circ}+\mathrm{H}_{2} \mathrm{O}\right)$ were detected as diagnostic product ions in the $\mathrm{MS}^{2}$ spectra. The $\mathrm{MS}^{2}$ spectrum of GA is shown in Figure 1.

\section{Identified metabolites}

The high-resolution extracted Ion Chromatography (HREIC) of blank, GA incubated in RLMS samples in 30 min are shown in the Figure 2. For the first time, a total of 12 metabolites of GA were detected and identified based on accurate mass measurements, fragmentation patterns, and chromatographic retention times in positive ion mode. The detailed information is illustrated in Table 1.

Metabolite M0, M8 and M12 were identified as GA, 5-hydroxy-7, 3', 4', 5'-tetramethoxyflavone and 5-hydroxy-7, 3', 4'-trimethoxyflavone, respectively by comparing the retention time, $[\mathrm{M}+\mathrm{H}]^{+}$ion and $\mathrm{MS}^{2}$ spectra with authentic references.

Metabolites M1, M2, M4, M6 and M7 were detected at $6.74,7.54,9.36,14.40$ and 16.44 min with protonated molecular ions $[\mathrm{M}+\mathrm{H}]^{+}$at $\mathrm{m} / \mathrm{z}$ $361.09153 \quad\left(-0.72 \mathrm{ppm}, \quad \mathrm{C}_{18} \mathrm{H}_{17} \mathrm{O}_{8}\right), \quad \mathrm{m} / \mathrm{z}$ 361.09164 (-0.43 ppm, $\left.\mathrm{C}_{18} \mathrm{H}_{17} \mathrm{O}_{8}\right), \quad \mathrm{m} / \mathrm{z}$ $361.09157 \quad\left(-0.61 \quad \mathrm{ppm}, \quad \mathrm{C}_{18} \mathrm{H}_{17} \mathrm{O}_{8}\right), \quad \mathrm{m} / \mathrm{z}$ 361.09171 (-0.22 ppm, $\left.\mathrm{C}_{18} \mathrm{H}_{17} \mathrm{O}_{8}\right)$, and $\mathrm{m} / \mathrm{z}$ 361.09168 (-0.30 ppm, $\left.\mathrm{C}_{18} \mathrm{H}_{17} \mathrm{O}_{8}\right), \quad 58$ Da $\left(2 \mathrm{CH}_{2}+\mathrm{OCH}_{2}\right)$ less than that of $\mathrm{GA}$. The diagnostic product ions at $m / z 346\left[\mathrm{M}+\mathrm{H}-\mathrm{CH}_{3}{ }^{\circ}\right]^{+}$, $\mathrm{m} / \mathrm{z} 314\left[\mathrm{M}+\mathrm{H}-3 \mathrm{CH}_{3}{ }^{\circ}\right]^{+}$, and $\mathrm{m} / z$ 329[M+H$\left.2 \mathrm{CH}_{3}{ }^{\circ}\right]^{+}$were detected. They were tentatively identified as 8, 3', 5'-trihydroxy-5, 7, 4'trimethoxyflavone, 5, 7, 3'-trihydroxy-8, 4', 5'trimethoxyflavone, 5, 8, 3'-trihydroxy-7, 4', 5'trimethoxyflavone, 5, 7, 4'-trihydroxy-8, 3', 5'- trimethoxyflavone, and 5, 8, 4'-trihydroxy-7, 3', 5'-trimethoxyflavone, respectively [16].

Metabolites M3 and M5 were detected at 7.54 and 12.97 min respectively, with the same quasimolecular ion $[\mathrm{M}+\mathrm{H}]^{+}$at $\mathrm{m} / \mathrm{z} 375.11\left(\mathrm{C}_{19} \mathrm{H}_{19} \mathrm{O}_{8}\right)$ that is $44 \mathrm{Da}\left(\mathrm{CH}_{2}+\mathrm{OCH}_{2}\right)$ less than the parent compound GA. The CID product-ion spectrum of $\mathrm{m} / \mathrm{z} 375$ displayed three major fragment ions at $m / z 360\left(\left[\mathrm{M}+\mathrm{H}-\mathrm{CH}_{3}\right]^{+}\right), \quad m / z 314\left(\left[\mathrm{M}+\mathrm{H}-2 \mathrm{CH}_{3}{ }^{-}\right.\right.$ $\left.\left.\mathrm{OCH}_{3}{ }^{\circ}\right]^{+}\right)$and $\mathrm{m} / \mathrm{z} 329\left(\left[\mathrm{M}+\mathrm{H}-\mathrm{CH}_{3}{ }^{\circ}-\mathrm{OCH}_{3}\right]^{+}\right)$. It was identified as the de-methoxylation and demethylation product of GA and were tentatively confirmed as 5, 4'-dihydroxy-7, 8, 3', 5'-tetramethoxyflavone and 5, 3'-dihydroxy-7, 8, 4', 5'tetramethoxyflavone, respectively [12].

Metabolite M9-M11 was eluted at 21.03, 21.60, and $22.00 \mathrm{~min}$, respectively. Each of them showed a protonated molecule ion at $\mathrm{m} / \mathrm{z} 389.12$ $\left(\mathrm{C}_{21} \mathrm{H}_{27} \mathrm{O}_{11}\right), 30 \mathrm{Da}\left(\mathrm{OCH}_{2}\right)$ more than that of parent drug. The fragment ions at $\mathrm{m} / \mathrm{z} 374$ (4.2 ppm, $\mathrm{C}_{6} \mathrm{H}_{9} \mathrm{O}_{7}$ ), m/z 359 (4.8 ppm, $\mathrm{C}_{6} \mathrm{H}_{9} \mathrm{O}_{7}$ ) and $\mathrm{m} / \mathrm{z} 356$ (4.8 ppm, $\mathrm{C}_{6} \mathrm{H}_{9} \mathrm{O}_{7}$ ) in the $\mathrm{MS}^{2}$ spectra of metabolite M9-M11, indicated that they were a pair of hydroxy-pentamethoxyflavone isomers. Based on examination of known polymethoxyflavonoids isolated from genus Murraya, and from bibliography data $[5,12], \mathrm{M} 9$ and $\mathrm{M} 10$ were tentatively identified as 5-hydroxy-6, 7, 3', 4', 5'pentamethoxyflavone, 5-hydroxy-6, 7, 8, 3', 4'pentamethoxyflavone, respectively. M11 was identified as hydroxypentamethoxy-flavone.

\section{DISCUSSION}

In the study, we identified metabolites of GA in vitro for the first time. These metabolites are polymethoxylated flavonoids with many methoxy groups (OH-PMFs), which facilitate their detection by ESI in positive mode. MS conditions were optimized on an UHPLC-ESI-LTQ-Orbitrap instrument using standard solution of GA (10 $\mu \mathrm{g} / \mathrm{mL})$. In order to obtain an appropriate elution system, two different mobile systems, acetonitrile - water and methanol - water were tested. It was found that for $\mathrm{GA},[\mathrm{M}+\mathrm{H}]^{+}$ions of basically the same intensity were commonly detected with high sensitivity with these two solvent conditions. However, the mobile systems of acetonitrile water with a gradient elution mode afforded much lower column pressure and better resolution of chromatographic peaks among the metabolites and endogenous components than that of water-methanol.

To our best knowledge, not much has been done on the elucidation of the metabolites of $\mathrm{GA}$, although some studies on the metabolism of $\mathrm{GA}$ 


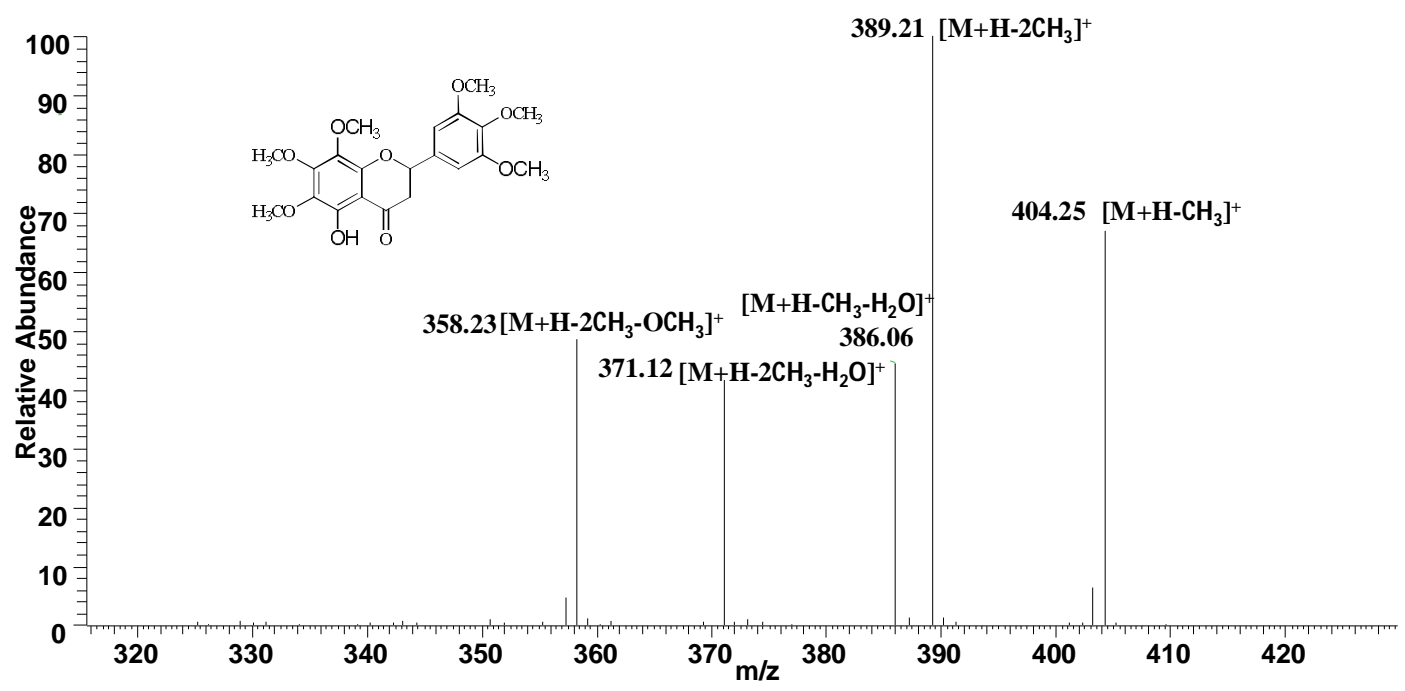

Figure 1: $\mathrm{MS}^{2}$ spectrum of $\mathrm{GA}$
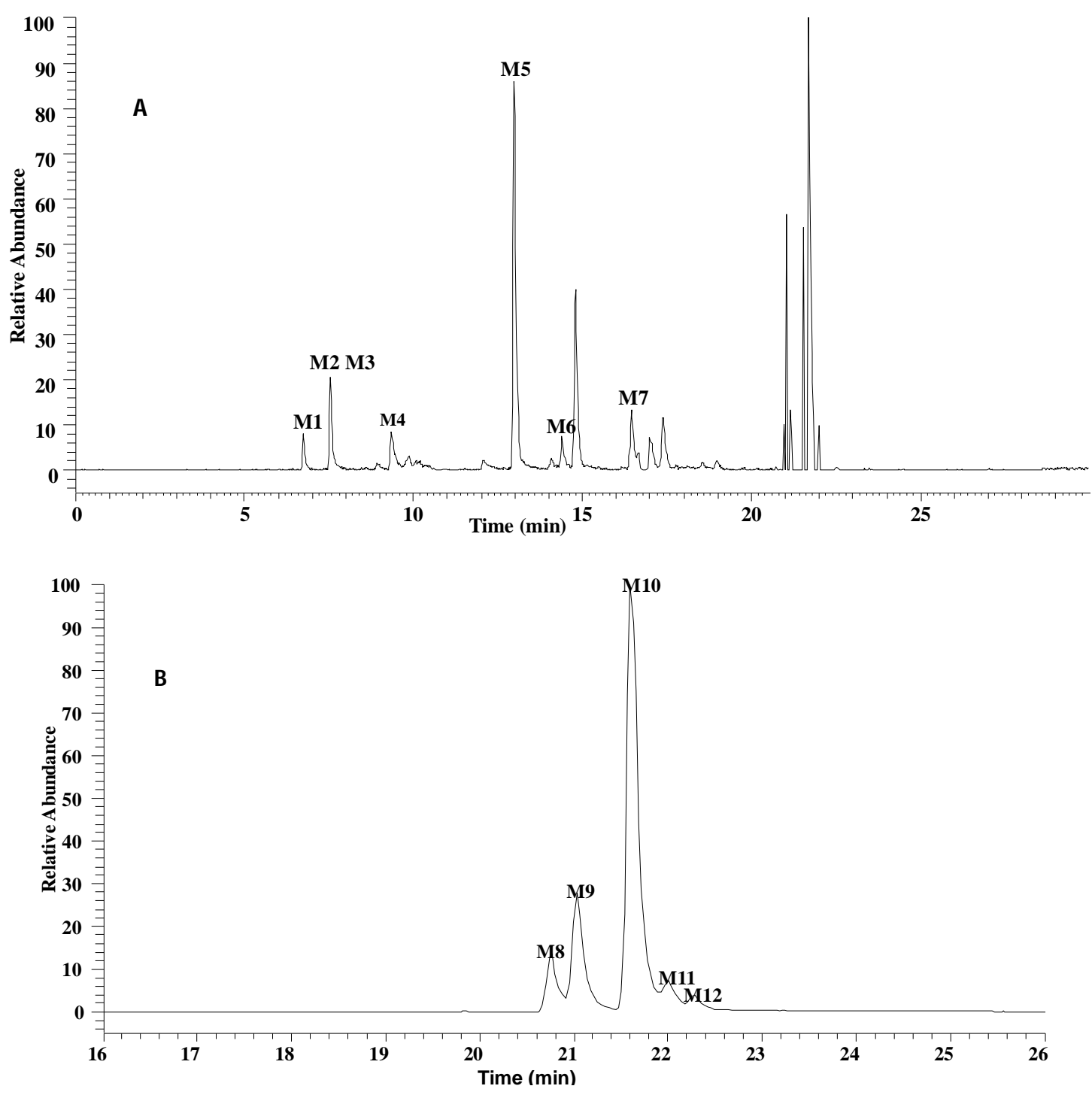

Figure 2: HREIC in $5 \mathrm{ppm}$ for the metabolites in RLMs (A) $\mathrm{m} / \mathrm{z} 361.09179,375.10744$; (B) $\mathrm{m} / \mathrm{z} 329.10196$, $359.11253,389.12259$ 
Table 1: Characteristic fragment ions of GA metabolites in RLMs by UHPLC-LTQ-Orbitrap MS

\begin{tabular}{|c|c|c|c|c|c|c|c|}
\hline Peak & $t_{R}$ & $\begin{array}{l}\text { Theoretical Mass } \\
\mathrm{m} / \mathbf{z}\end{array}$ & $\begin{array}{l}\text { Experimental Mass } \\
\mathrm{m} / \mathbf{z}\end{array}$ & $\begin{array}{l}\text { Error } \\
(\mathrm{ppm})\end{array}$ & $\begin{array}{c}\text { Formula [M- } \\
\mathrm{H}^{-}\end{array}$ & MS/MS fragment & Identification \\
\hline 0 & 22.76 & 419.13269 & 419.13321 & -1.071 & $\mathrm{C}_{21} \mathrm{H}_{23} \mathrm{O}_{9}$ & $\begin{array}{c}\mathrm{MS}^{2}[419]: 389(100), 404(65), 358(40) \\
371(38), 386(37)\end{array}$ & gardenin A \\
\hline 1 & 6.74 & 361.09179 & 361.09153 & -0.717 & $\mathrm{C}_{18} \mathrm{H}_{17} \mathrm{O}_{8}$ & $\mathrm{MS}^{2}$ [361]: 346(100), 314(26), 329(15) & $\begin{array}{l}\text { 8, 3', 5'-trihydroxy-5, 7, 4'- } \\
\text { trimethoxyflavone }\end{array}$ \\
\hline 2 & 7.54 & 361.09179 & 361.09164 & -0.426 & $\mathrm{C}_{18} \mathrm{H}_{17} \mathrm{O}_{8}$ & $\mathrm{MS}^{2}[361]: 346(100)$ & $\begin{array}{l}5,7,3^{\prime} \text {-trihydroxy-8, 4', 5'- } \\
\text { trimethoxyflavone }\end{array}$ \\
\hline 3 & 7.54 & 375.10744 & 375.10721 & -0.624 & $\mathrm{C}_{19} \mathrm{H}_{19} \mathrm{O}_{8}$ & $\begin{array}{c}\mathrm{MS}^{2}[375]: 360(100), 314(82), 329(49) \\
347(19)\end{array}$ & $\begin{array}{l}\text { 5, 4'-dihydroxy-7, 8, 3', 5'- } \\
\text { tetramethoxyflavone }\end{array}$ \\
\hline 4 & 9.36 & 361.09179 & 361.09157 & -0.606 & $\mathrm{C}_{18} \mathrm{H}_{17} \mathrm{O}_{8}$ & $\mathrm{MS}^{2}[361]: 346(100)$ & $\begin{array}{l}\text { 5, 8, 3'-trihydroxy-7, 4', 5'- } \\
\text { trimethoxyflavone }\end{array}$ \\
\hline 5 & 12.97 & 375.10744 & 375.10708 & -0.957 & $\mathrm{C}_{19} \mathrm{H}_{19} \mathrm{O}_{8}$ & $\mathrm{MS}^{2}[375]: 360(100)$ & $\begin{array}{l}\text { 5, 3'-dihydroxy-7, 8, 4', 5'- } \\
\text { tetramethoxyflavone }\end{array}$ \\
\hline 6 & 14.40 & 361.09179 & 361.09171 & -0.218 & $\mathrm{C}_{18} \mathrm{H}_{17} \mathrm{O}_{8}$ & $\mathrm{MS}^{2}[361]: 329(100), 346(8)$ & $\begin{array}{l}\text { 5, 7, 4'-trihydroxy-8, 3', 5'- } \\
\text { trimethoxyflavone }\end{array}$ \\
\hline 7 & 16.44 & 361.09179 & 361.09168 & -0.301 & $\mathrm{C}_{18} \mathrm{H}_{17} \mathrm{O}_{8}$ & $\mathrm{MS}^{2}[361]: 346(100)$ & $\begin{array}{l}5,8,4^{\prime} \text {-trihydroxy-7, 3', 5'- } \\
\text { trimethoxyflavone }\end{array}$ \\
\hline 8 & 20.77 & 359.11253 & 359.11206 & -1.307 & $\mathrm{C}_{19} \mathrm{H}_{19} \mathrm{O}_{7}$ & $\mathrm{MS}^{2}[359]: 344(100), 343(26), 315(15)$ & $\begin{array}{l}\text { 5-hydroxy-7, 3', 4', 5'- } \\
\text { tetramethoxyflavone }\end{array}$ \\
\hline 9 & 21.03 & 389.12259 & 389.12309 & -1.295 & $\mathrm{C}_{20} \mathrm{H}_{21} \mathrm{O}_{8}$ & $\begin{array}{c}\mathrm{MS}^{2}[389]: 356(100), 328(72), 374(70) \\
359(15)\end{array}$ & $\begin{array}{l}\text { 5-hydroxy-6, 7, 3', 4', 5'- } \\
\text { pentamethoxyflavone }\end{array}$ \\
\hline 10 & 21.60 & 389.12259 & 389.12234 & -1.938 & $\mathrm{C}_{20} \mathrm{H}_{21} \mathrm{O}_{8}$ & $\begin{array}{c}\mathrm{MS}^{2}[389]: 359(100), 374(75), 356(45), \\
341(41)\end{array}$ & $\begin{array}{l}\text { 5-hydroxy- } 6,7,8,3 ', 4 '- \\
\text { pentamethoxyflavone }\end{array}$ \\
\hline 11 & 22.00 & 389.12259 & 389.12283 & -0.679 & $\mathrm{C}_{20} \mathrm{H}_{21} \mathrm{O}_{8}$ & $\begin{array}{c}\mathrm{MS}^{2}[389]: 374(100), 328(74), 359(48), \\
356(21)\end{array}$ & hydroxy-pentamethoxyflavone \\
\hline 12 & 22.29 & 329.10196 & 329.10159 & -1.139 & $\mathrm{C}_{18} \mathrm{H}_{17} \mathrm{O}_{6}$ & $\mathrm{MS}^{2}[329]: 313(100), 314(77), 285(34)$ & 5-hydroxy-7, 3', 4'-trimethoxyflavone \\
\hline
\end{tabular}


have been done in rats [12]. For example, 26 metabolites of GA were unambiguously and tentatively identified in Sprague-Dawley rats by comparison of retention times and mass spectrometry. However, it is worth mentioning that in vitro metabolites of $\mathrm{GA}$; and the differences between in vivo and in vitro metabolites of GA were still unclear until now. In our study, 12 metabolites were detected and identified in RLMs. There was a good agreement between these metabolites and those obtained in in vivo studies. This clearly shows that it is feasible to obtain metabolites of GA in vitro.

\section{CONCLUSION}

This study has successfully elucidated the in vitro metabolism of GA in RLMs using UHPLC-LTQOrbitrap mass spectrometry. Among the 12 metabolites detected, 3 have been unambiguously confirmed, while the others are tentatively identified. The structures clearly indicate that de-methoxylation and demethylation are the major metabolic fates of GA. These metabolites of GA in RLMs would facilitate better understanding of the metabolism and its pharmacological effects.

\section{DECLARATIONS}

\section{Acknowledgement}

The authors gratefully acknowledge $\mathrm{Dr} \mathrm{Di}$ Jia for supporting this project.

\section{Conflict of Interest}

No conflict of interest associated with this work.

\section{Contribution of Authors}

The authors declare that this work was done by the authors named in this article and all liabilities pertaining to claims relating to the content of this article will be borne by them.

\section{Open Access}

This is an Open Access article that uses a funding model which does not charge readers or their institutions for access and distributed under the terms of the Creative Commons Attribution License (http://creativecommons.org/licenses/by 14.0) and the Budapest Open Access Initiative (http://www.budapestopenaccessinitiative.org/rea d), which permit unrestricted use, distribution, and reproduction in any medium, provided the original work is properly credited.

\section{REFERENCES}

1. Chinese Pharmacopoeia Commission. Pharmacopoeia of the People's Republic of China, vol.1 China Medical Science Press, Beijing, China; 2015; $p 10$.

2. Anonymous. The wealth of India: The raw materials. Vol VI, India, CSIR, 1962; pp 446-448.

3. Perry LM. Medicinal Plants of East and Southeast Asia: Attributed Properties and Uses. England: MIT Press, 1980; $p 367$.

4. Ghani A. Medicinal plants of Bangladesh: Chemical constituents and uses. 2nd edn. Dhaka, Asiatic Society of Bangladesh, 2003; pp 309-310.

5. Kinoshita T, Firman K. Highly oxygenated flavonoids from Murraya paniculata. Phytochemistry 1996; 42(4): 12071210.

6. Li SM, Pan MH, Lai CS, Lo CY, Dushenkov S, Ho CT. Isolation and syntheses of polymethoxyflavones and hydroxylated polymethoxyflavones as inhibitors of HL-60 cell lines. Bioorg Med Chem 2007; 15(10): 3381-3389.

7. Lai CS, Li S, Chai CY, Lo CY,Ho CT, Wang YJ, Pan MH. Inhibitory effect of citrus 5-hydroxy-3, 6, 7, 8,3', 4'hexamethoxyflavone on 12-O-tetradecanoylphorbol 13acetate-induced skin inflammation and tumor promotion in mice. Carcinogenesis 2007; 28: 2581-2588.

8. Xiao H,Yang CS, Li S, Jin H, Ho CT, Patel $T$. Monodemethylated polymethoxyflavones from sweet orange (Citrus sinensis) peel inhibit growth of human lung cancer cells by apoptosis. Mol Nutr Food Res 2009; 53: 398-406.

9. Pan MH, Lai YS, Lai CS,Wang YJ, Li S, Lo CY, Dushenkov S, Ho CT. 5-Hydroxy-3, 6, 7, 8, 3', 4'hexamethoxyflavone induces apoptosis through reactive oxygen species production, growth arrest and DNA damage-inducible gene 153 expression, and caspase activation in human leukemia cells. J Agr Food Chem 2007; 55: 5081-5091.

10. Lu A H. Drug-Metabolism research challenges in the new millennium individual variability in drug therapy and drug safety. Drug Metab Dispos 1998; 26(12): 1217-1222.

11. Masimirembwa $C M$, Otter $C$, Berg $M$, Jönsson $M$, Leidvik $B$, Jonsson $E$, Johansson $T$, Bäckman $A$, Edlund $A$, Andersson TB. Heterologous expression and kinetic characterization of human cytochromes $P-450$ : validation of a pharmaceutical tool for drug metabolism research. Drug Metab Dispos 1999; 27(10): 1117-1122.

12. Zhang J, Wang F, Cai W, Zhang Q, Liu Y, Li Y, Liu RR, Cao GS. Identification of metabolites of gardenin $A$ in rats by combination of high-performance liquid chromatography with linear ion trap-Orbitrap mass spectrometer based on multiple data processing techniques. Biomed Chromatogr 2015; 29(3): 379-387.

13. Wu FP, Yang $Y$, Liu LH, Pu H, Jin P, Yao ZF, Cai W. Profiling and Identification of the Metabolites of Evodiamine in Rats using Ultra-Performance Liquid Chromatography with Linear Ion Trap Orbitrap Mass Spectrometer. Trop J Pharm Res 2016; 15(3): 623-629. 
14. Dunn WB, Broadhurst D, Brown M, Baker PN, Edman CWG, Kenny LC, Kell DB. Metabolic profiling of serum using Ultra Performance Liquid Chromatography and the LTQ-Orbitrap mass spectrometry system. J Chromatogr B 2008; 871(2): 288-298.

15. Peterman SM, Duczak N, Kalgutkar AS, Lame ME, Soglia JR. Application of a linear ion trap/orbitrap mass spectrometer in metabolite characterization studies: examination of the human liver microsomal metabolism of the non-tricyclic anti-depressant nefazodone using data-dependent accurate mass measurements. J Am Soc Mass Spect 2006; 17(3): 363-375.

16. Zhang XF, Hu BL, Zhou BN. Studies on the Active Constituents of Tibetan Herb Biebersteinia heterostemon Maxim. Acta Pharm Sin 1995; 30: 214214. 